\title{
The impact of nutritional counseling on thyroid disorders in head and neck cancer patients after (chemo)radiotherapy: results from a prospective interventional trial
}

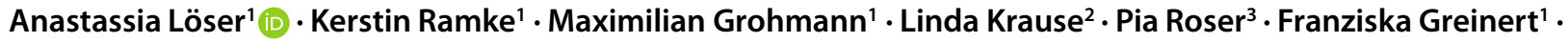 \\ Anna Finger ${ }^{1}$ - Margaret Sommer ${ }^{1}$ Eva Culmann ${ }^{1}$ - Tessa Lorenz ${ }^{1}$ Saskia Becker ${ }^{1}$. Marvin Henze ${ }^{1}$. \\ Daniel Schodrok ${ }^{1} \cdot$ Julia von Grundherr ${ }^{4} \cdot$ Silke Tribius $^{5}$ • Andreas Krüll1,6 • Cordula Petersen ${ }^{1,6}$
}

Received: 17 June 2021 / Accepted: 3 October 2021 / Published online: 1 November 2021

(c) The Author(s) 2021, corrected publication 2021

\begin{abstract}
Objective To analyze the impact of nutritional counseling on the development of hypothyroidism after (chemo)radiotherapy in head and neck cancer patients to propose a new normal tissue complication probability (NTCP) model.

Materials and methods At baseline, at the end of (chemo)radiotherapy, and during follow-up, thyroid-stimulating hormone (TSH) with free thyroxin (fT3 and fT4), nutritional status, and nutrient intake were prospectively analyzed in 46 out of 220 screened patients. Patients received (chemo)radiotherapy within an intervention (individual nutritional counseling every 2 weeks during therapy) and a control group (no nutritional counseling).

Results Overall median follow-up was 16.5 [IQR: 12; 22] months. Fourteen patients $(30.4 \%)$ presented with hypothyroidism after 13.5 [8.8; 17] months. During (chemo)radiotherapy, nutritional status worsened in the entire cohort: body mass index $(p<0.001)$ and fat-free mass index $(p<0.001)$ decreased, calorie deficit $(p=0.02)$ increased, and the baseline protein intake dropped $(p=0.028)$. The baseline selenium intake $(p=0.002)$ increased until the end of therapy. Application of the NTCP models by Rønjom, Cella, and Boomsma et al. resulted in good performance of all three models, with an AUC ranging from 0.76 to 0.78 . Our newly developed NTCP model was based on baseline TSH and baseline ferritin. Model performance was good, receiving an AUC of 0.76 (95\% CI: $0.61-0.87)$, with a sensitivity of $57.1 \%$ and specificity of $96.9 \%$ calculated for a Youden index of $0.73(p=0.004$; area $=0.5)$.

Conclusion Baseline TSH and ferritin act as independent predictors for radiotherapy-associated hypothyroidism. The exclusion of such laboratory chemistry parameters in future NTCP models may result in poor model performance.
\end{abstract}

Keywords Thyroid gland · Normal tissue complication probability (NTCP) model · Chemoradiotherapy · Radiotherapy · Hypothyroidism

Trial registration number: German Clinical Trials Register (DRKS00016862).

Date of trial registration: 03/11/2019

Availability of data and material: Research data are stored in an institutional repository and will be shared upon request to the corresponding author.

Anastassia Löser, MD

an.loeser@uke.de

1 Outpatient Center of the UKE GmbH, Department of Radiotherapy and Radiation Oncology, University Medical Center Hamburg-Eppendorf, Martinistraße 52, 20246 Hamburg, Germany

2 Institute of Medical Biometry and Epidemiology, University Medical Center Hamburg-Eppendorf, Martinistraße 52, 20246 Hamburg, Germany
3 Center for Internal Medicine, Department of Nephrology, Rheumatology and Endocrinology, University Medical Center Hamburg-Eppendorf, Martinistraße 52, 20246 Hamburg, Germany

4 University Medical Center Hamburg-Eppendorf, University Cancer Center Hamburg (UCCH), Martinistraße 52, 20246 Hamburg, Germany

5 Hermann Holthusen Institute for Radiation Oncology, Asklepios Hospital St. Georg, Lohmühlenstraße 5, 20099 Hamburg, Germany

6 Department of Radiotherapy and Radiation Oncology, University Medical Center Hamburg-Eppendorf, Martinistraße 52, 20246 Hamburg, Germany 


\section{Introduction}

Although radiotherapy constitutes a curative therapeutic approach for squamous cell carcinoma of the head and neck (HNSCC), it is often associated with a significant dose to the thyroid gland. Radiotherapy-induced thyroid dysfunction can lead to primary manifest hypothyroidism (low free thyroxin [fT4] and elevated thyroid-stimulating hormone [TSH]) or subclinical (normal fT4 and elevated TSH) hypothyroidism, Hashimoto's thyroiditis, or Graves' disease. Primary hypothyroidism is considered the most common radiotherapy-induced thyroid disorder and affects $20-60 \%$ of patients receiving irradiation to the neck $[1,2]$. It usually occurs within 5 years after therapy completion [1]. Prior thyroidectomy and the applied irradiation dose are risk factors for hypothyroidism [1, 3, 4]. A mean thyroid dose $\left(D_{\text {mean }}\right)$ of $\leq 30$ Gy is considered an important threshold dose for maintaining thyroid function [5]. Also, a V45Gy of less than $50 \%$ and more than $50 \%$ is associated with a 1-year incidence of hypothyroidism of $22.8 \%$ and $56.1 \%$, respectively [6]. Apart from the applied radiation dose, the occurrence of hypothyroidism correlates with a reduction in thyroid volume $[2,7,8]$.

In addition to dosimetric factors, deficiency symptoms of certain macro- and micronutrients may occur in the context of tumor- or treatment-related malnutrition, favoring the development of hypothyroidism [9]: Among these are iodine (important component of fT3 and fT4), iron (required for thyroid hormone formation) [9-13], selenium (regulation of the conversion of fT4 to fT3) [14], and amino acids (needed for the formation of free thyroid hormones) [15].

Between 3 and $52 \%$ of patients with HNSCC are malnourished before therapy initiation [16-18]. Treatment-related toxicity often leads to further progression of malnutrition to as much as $88 \%[16,17]$. Apart from nutritional screening tools and anthropometric methods (e.g., BMI, calf circumference), bioelectrical impedance analysis (BIA) is becoming increasingly established to assess nutritional status and measure body composition.

Data on thyroid disorders in head and neck cancer patients undergoing (chemo)radiotherapy receiving nutritional intervention are completely lacking. The aim of this prospective intervention study was to identify possible predictors of hypothyroidism by considering dosimetric as well as clinical and nutritional factors to propose a new multivariable normal tissue complication probability (NTCP) model to predict radiation-induced hypothyroidism [7, 19].

\section{Methods}

\section{Study design}

The data analyzed for this study were prospectively obtained during a monocentric, controlled randomized (1:1) intervention study performed at the University Medical Center Hamburg-Eppendorf. This prospective trial was named "HEADNUT-trial" standing for head and neck cancer patients undergoing nutritional intervention [20]. This work focuses on radiotherapy-induced hypothyroidism and the impact of nutritional indicators to develop a new multivariable predictive model.

Patient recruitment was initiated in October 2018. Due to the upcoming corona pandemic, recruitment was paused between March and August 2020, and was later continued until October 2020. This study was approved by the local ethics committee (PV5818) and registered within the German Clinical Trials Register (DRKS00016862). All patients signed written informed consent.

This study consists of a control group and an intervention group. Patients within the intervention group received personalized nutritional counseling during (chemo)radiotherapy.

\section{Patient recruitment}

Eligible patients presented with squamous cell carcinoma of the oropharynx, oral cavity, hypopharynx, larynx, or salivary glands, showing an euthyroid metabolic status at baseline. Exclusion criteria included another solid tumor within the last 15 years, palliative intent, a Karnofsky performance status below $60 \%$, and pacemakers (as a relative contraindication for BIA).

\section{Laboratory analyses}

The following laboratory parameters were measured in all patients at the beginning and the end of therapy: hemoglobin (normal range: $12.3-15.3 \mathrm{~g} / \mathrm{dL}$ ), TSH (normal range: $1.56-4.78 \mathrm{mU} / \mathrm{L}$ ), fT4 (normal range: 11.5 $22.7 \mathrm{pmol} / \mathrm{L}$ ), fT3 (normal range: $3.5-6.5 \mathrm{pmol} / \mathrm{L}$ ), ferritin level (normal range: 10-291 $\mu \mathrm{g} / \mathrm{L}$ ), and total protein (normal range: $57-82 \mathrm{~g} / \mathrm{L}$ ). During follow-up, TSH levels were prospectively collected at least once per year.

\section{Assessment of nutritional status}

In both treatment arms, nutritional status was documented at the beginning and at the end of therapy. At both timepoints, all patients were clinically examined by a radiation oncologist and a dietician specialized in oncology assessed the individual nutritional risk profile (including anthropometric data with height and weight). Additionally, BIA (Biacor- 
pus RX4004M; MEDI CAL HealthCare GmbH, Karlsruhe, Germany) was performed in all patients [21] and a 3-day food diary was submitted. Nutrient and calorie intake was interpreted by DGExpert software (v1.3.14.1, German Society for Nutrition [DGE], Bonn, Germany).

Only patients of the intervention group received nutritional consultations (lasting for $30 \mathrm{~min}$ ) every 2 weeks with personalized nutritional recommendations based on their anthropometric measurements including BIA, their submitted food diaries, their clinical condition, the severity of potential therapy-associated side effects, and results from laboratory analyses.

Malnutrition was defined at a BMI of $<18.5 \mathrm{~kg} / \mathrm{m}^{2}$ and a BIA-derived fat-free mass (FFM) index (FFMI = FFM/ height $^{2}$ ) of $<15$ and $<17 \mathrm{~kg} / \mathrm{m}^{2}$ in women and men, respectively [22]. Also, the phase angle was obtained from BIA $[23,24]$.

\section{Treatment planning, dosimetry, and (chemo)radiotherapy}

A contrast-enhanced planning CT (Somatom, Siemens Healthcare, Forchheim, Germany) was obtained at 3-mm slice thickness for each patient in supine position. Target volume and normal tissue contouring was performed on the planning CT using Eclipse (v15.1, Varian Medical Systems, Inc., Palo Alto, CA, US). During treatment planning, no dose restrictions to the thyroid gland were defined. For dosimetric evaluation, a corresponding dose-volume histogram $(\mathrm{DVH})$, the thyroid volume, the mean $\left(\mathrm{D}_{\text {mean }}\right)$, the minimum dose $\left(\mathrm{D}_{\min }\right)$, and the maximum thyroid dose $\left(D_{\max }\right)$ were recorded. Also, $V_{10}, V_{20}, V_{30}, V_{40}, V_{45}, V_{50}, V_{60}$, and $V_{70}$ were calculated $[6,7] . \mathrm{CV}_{\mathrm{x}}\left(\mathrm{cm}^{3}\right)$ is defined as the thyroid volume $\left(\mathrm{cm}^{3}\right)$ that received $\leq \mathrm{x}$ Gy. We determined $\mathrm{CV}_{10}, \mathrm{CV}_{20}, \mathrm{CV}_{30}$, and $\mathrm{CV}_{40}[5,25]$.

The thyroid gland was contoured on the planning CT and on all available pretherapeutic MRIs and on all follow-up CT and MRI scans using Eclipse. For the subsequent pre- versus postherapeutic comparison of thyroid volumes, intermodal comparison was excluded, so only MRI scans were compared with MRI scans and CT scans with CT scans. To rule out interobserver variability, all thyroid glands were contoured by the same physician.

Radiotherapy was prescribed as intensity-modulated radiotherapy (IMRT) in single fractions of 1.7 to $2.0 \mathrm{~Gy}$, five times per week, to cumulative doses from 60 to $70.4 \mathrm{~Gy}$ [26, 27]. For concomitant chemotherapy, either 3 -weekly cycles of cisplatin $100 \mathrm{mg} / \mathrm{m}^{2}$, weekly cisplatin $40 \mathrm{mg} / \mathrm{m}^{2}$, or a regimen with concomitant 5 -fluorouracil $\left(5-\mathrm{FU} ; 600 \mathrm{mg} / \mathrm{m}^{2}\right.$ on days 1 to 5$)$ and mitomycin $\mathrm{C}\left(10 \mathrm{mg} / \mathrm{m}^{2}\right.$ on days 5 and 36$)$ was followed.

\section{Clinical and radiological follow-up}

The first radio-oncological exam and the first follow-up MRI or CT (in case of contraindications for MRI) of the head and neck area were performed 6-8 weeks after therapy completion. A BIA measurement was also taken at this time. MRI/CT imaging of the head and neck area was repeated once per year along with a CT scan of the chest and abdomen. Radio-oncological follow-up examinations occurred semiannually.

\section{Statistical analyses}

Our endpoint was defined as the occurrence of hypothyroidism (elevated TSH value: $>4.78 \mathrm{mU} / \mathrm{L}$ ) at any time during follow-up. We did not differentiate between manifest and subclinical hypothyroidism. Follow-up started from the date of initial diagnosis of HNSCC.

The difference between the actual calorie intake and the calculated required calorie intake needed to maintain body weight (kcal) was defined as "calorie deficit" ( $\Delta$ calorie deficit). The difference between a measured baseline value and the same value at the end of therapy was referred to as " $\Delta$ " in each case (e.g., $\Delta$ iodine intake = baseline iodine intake - iodine intake at therapy completion).

Normally distributed values were expressed as means with standard deviations $( \pm \mathrm{SD})$, and nonnormally distributed variables were expressed as medians (interquartile range $[\mathrm{IQR}]$ with first and third quartiles). To evaluate differences within a $2 \times 2$ contingency table, Fisher's exact test was chosen. In case of cross-tabulations with more variables, chi-square test was used. To test for differences between two independent samples, Mann-Whitney U test was applied. To compare the association between mean ranks, Wilcoxon-signed rank test was used.

The following logistic regression-based model has been described previously by several authors [7, 28, 29]:

$N T C P=\left(1+e^{-S}\right)^{-1}$, in which

$S=\beta_{0}+\beta_{1} \cdot x_{1}+\ldots+\beta_{n} \cdot x_{n}$

$\beta_{0}$ is the constant from the multivariable logistic regression model, while $\beta_{n}$ is the regression coefficient multiplied with the corresponding input variable $x_{n}$.

To estimate whether this logistic regression-based model is also suitable for the present dataset, we applied the NTCP models by Rønjom, Cella, and Boomsma et al. using MedCalc (version 19.6, MedCalc Software Ltd, Ostend, Belgium) [7, 28, 29]. Univariable logistic regression analyses were performed with SPSS (version 25.0, IBM Corp., Armonk, NY, US) and all variables shown in Table 2 were tested individually for differences in the endpoint. We established four separate multivariable regression models. In 
all four models, all variables from our univariable regression analyses with a $p<0.05$ (baseline iodine intake, $\Delta$ iodine intake, baseline TSH and ferritin, as well as TSH and ferritin level at the end of therapy) were entered. As this was an interventional study, the first model also contained the study arm as a possible influencing factor. In models $2-4$, the study arm was neglected because it did not show a $p<0.05$ in univariable regression analysis. Additionally, dosimetrically relevant parameters from previously published NTCP models or known influencing factors were included in models 1-3 (mean thyroid dose, baseline thyroid volume, V45 Gy, and V30Gy) [6, 7, 28, 29]. The multivariable regression model was estimated in MedCalc by applying stepwise backward selection. Only parameters with a $p<0.05$ remained within the model. All entered parameters from the multivariable logistic regression analysis were checked not to interact with each other by means of Spearman's rank correlation coefficient.

We chose the area under the curve (AUC) from receiver operating characteristics (ROC) as a performance measurement of our prediction model [30]. An AUC of 0.8-1 is considered excellent, an AUC of 0.7-0.8 means good performance, less than 0.7 is considered suboptimal, and an AUC of 0.5 corresponds to an unusable model. Cutoff values (e.g., for phase angle) were derived from ROC by calculating a Youden index.

For DVH mapping of the thyroid gland, the software tool DVH Analytics by Cutright et al. was employed [31]. Kaplan-Meier method was used to calculate the cumulative incidence of hypothyroidism and the overall survival applying MedCalc.

\section{Results}

\section{Patients}

Between October 2018 and October 2020, 220 patients were screened for eligibility. 174 patients were considered unsuitable (see CONSORT diagram, Fig. 1). Clinical data from the remaining 46 patients were investigated.

In all patients, median age was 63 [57; 73] years with a predominance of male patients of approximately $2: 1$. Baseline patient characteristics are shown in Table 1. Overall follow-up was $16.5[12 ; 22]$ months and TSH-specific follow-up was 13.5 [8.8; 17] months (see Fig. 2).

\section{Analysis of thyroid function}

At baseline, all patients were euthyroid. Median baseline TSH was $1.3[1 ; 2] \mathrm{mU} / \mathrm{L}$ and decreased to $0.9[0.4$; $1.9] \mathrm{mU} / \mathrm{L}$ (reference: $0.55-4.78 \mathrm{mU} / \mathrm{L}$ ) until therapy end $(p=0.02)$. At the end of therapy, only 1 patient in the control group presented with an elevated TSH level $(p=1)$, while 6 patients in each therapy arm had suppressed TSH levels below $0.55 \mathrm{mU} / \mathrm{L}(p=1)$. During follow-up, 3 of these 12 patients with suppressed TSH levels developed subclinical or manifest hypothyroidism, 5 became euthyroid, and in 4 cases no follow-up TSH value was obtainable. Overall, 9 patients of the intervention and 5 patients of the control group presented with elevated TSH values (without differentiating between manifest and subclinical forms) during follow-up $(p=0.202)$. These 14 patients presented with a median TSH of $7.04[5.45 ; 8.23] \mathrm{mU} / \mathrm{L}$. For hypothyroidism, cumulative percentage for the 1- and 2-year incidence was $21.3 \%$ and $85.9 \%$, respectively (see Fig. 2).

\section{Analysis of nutritional status}

For all patients $(n=46)$, median baseline BMI was 23 [21; $27.5] \mathrm{kg} / \mathrm{m}^{2}$ and dropped to $22.2[20.8 ; 25.2] \mathrm{kg} / \mathrm{m}^{2}$ at the end of therapy $(p<0.001)$. No differences in BMI reduction were found between the treatment arms $(p=0.36)$. Baseline FFMI and phase angle were $18[16.2 ; 20.1] \mathrm{kg} / \mathrm{m}^{2}$ and $5.2[4.7 ; 6.1]^{\circ}$, respectively. At therapy completion, both measured values dropped to $17.4[15.5 ; 17.4] \mathrm{kg} / \mathrm{m}^{2}$ and $5[4.4 ; 5.9]^{\circ}$ for median FFMI $(p<0.001)$ and phase angle $(p=0.2)$, respectively. The pre- versus posttherapeutic changes in FFMI and phase angle did not differ between the study arms (FFMI: $p=0.57$; phase angle: $p=0.59$ ). Until the end of therapy, the baseline median $\Delta$ calorie deficit increased from 117.8 [-439; 708.7] kcal to -539.6 [-672.6; $109] \mathrm{kcal}$ under ongoing (chemo)radiotherapy in the entire patient cohort $(p=0.02)$.

In all patients, no relevant differences between the median baseline iodine intake of 138 [88.5; 201.8] $\mu \mathrm{g}$ and $133[80.5 ; 204] \mu \mathrm{g}$ at therapy completion were observed $(p=0.92)$, while the baseline median oral protein intake decreased from $84[62.3 ; 108.4] \mathrm{g}$ to 70.6 [46.5; 87.4]g $(p=0.028)$. The overall iron intake was $11[8.9 ; 17.6] \mathrm{mg}$ at baseline and fell to $11.9[7.9 ; 14.1] \mathrm{mg}$ at the end of therapy $(p=0.8)$. Initially, overall oral selenium intake was measured to be $0[0 ; 35.4] \mu \mathrm{g}$ at baseline and $39.2[0 ; 67] \mu \mathrm{g}$ at the end of therapy $(p=0.002)$. Considering pre- and posttherapeutic changes $(\Delta \mathrm{x})$, we did not observe relevant differences between the study arms ( $\Delta$ iodine intake: $p=0.76$; $\Delta$ protein intake: $p=0.36 ; \Delta$ iron intake: $p=0.8 ; \Delta$ selenium intake: $p=0.21$ ).

In all patients, baseline ferritin was $126.9[54 ; 277.5] \mu \mathrm{g} / \mathrm{L}$ and increased to $237[86 ; 417] \mu \mathrm{g} / \mathrm{L}$ by the end of therapy $(p=0.001)$, without differences between the treatment arms $(p=0.11)$. Within the entire cohort, baseline hemoglobin was $12.8[11.8 ; 14.0] \mathrm{g} / \mathrm{dL}$ and baseline total protein $72.2[68.9 ; 87.3] \mathrm{g} / \mathrm{L}$. Both parameters decreased, to $11.1[9.8 ; 13.1] \mathrm{g} / \mathrm{dL}$ (for hemoglobin: $p<0.001$ ) and to $68[62.3 ; 71.5] \mathrm{g} / \mathrm{L}$ (total protein: $p<0.001$ ). 
Fig. 1 Consort diagram on patient selection [36]. Nutritional data and the initial screening of all 61 patients have been described previously elsewhere [20]

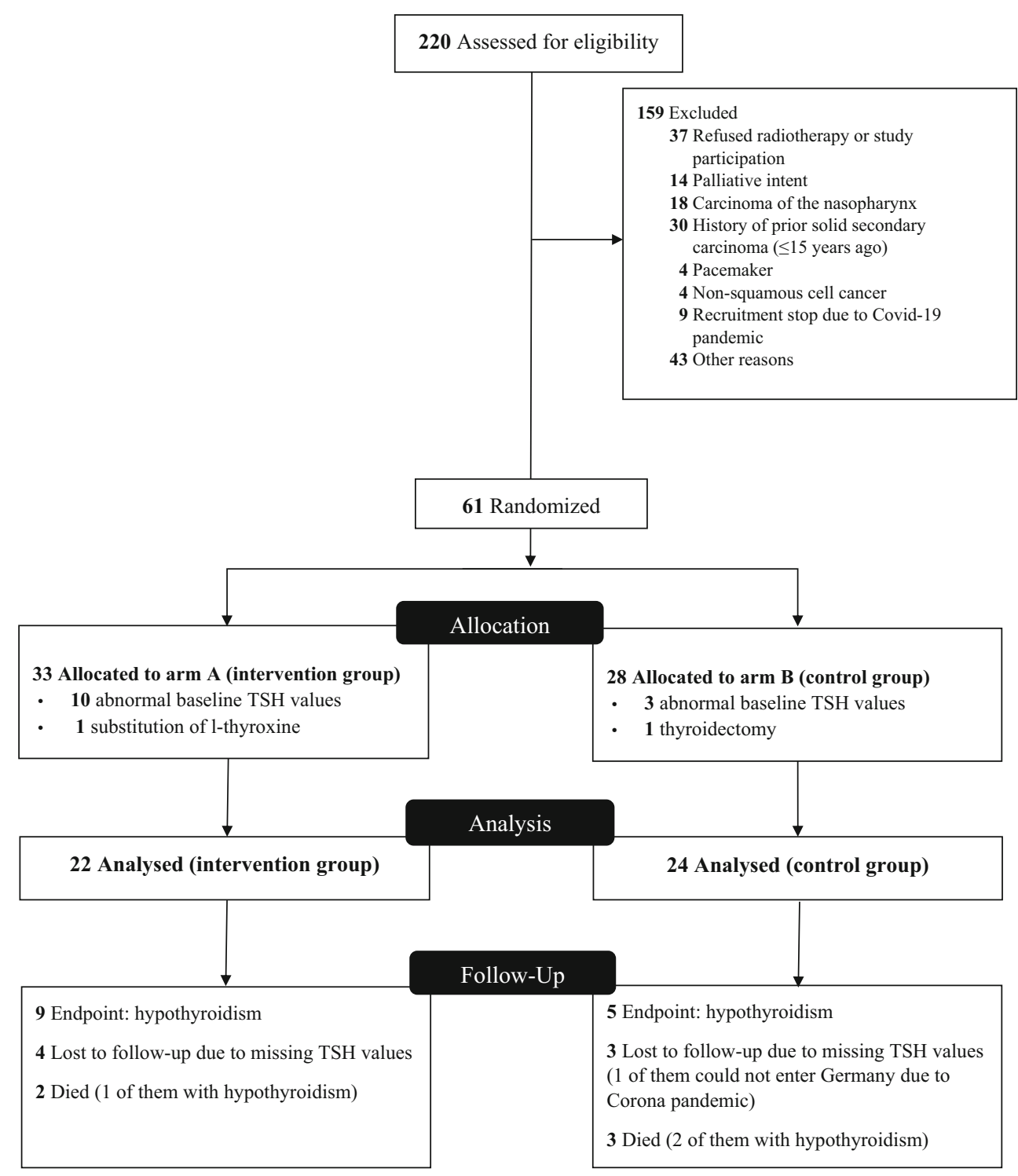

\section{Volumetric and dosimetric evaluation}

In all 46 planning CTs, median thyroid volume was $14.7[9.9 ; 21] \mathrm{cm}^{3}$. Additionally, 114 thyroid glands were contoured on pre- and posttherapeutic MRIs and CTs: An intramodal comparison by means of pre- and posttherapeutic MRI comparing thyroid volume was possible in 19 patients $(41.3 \%)$, and pre- and posttherapeutic CT in 10 patients $(21.7 \%) .17$ patients $(37 \%)$ were not included into this subanalysis, 5 (10.9\%) of whom had died during follow-up. In the remaining 12 cases, either only an intermodal comparison would have been possible, or patients did not receive further radiological follow-up examinations. The median time interval between these pre- and posttherapeutic radiological examinations was 9 [5; 15] months. At baseline, the MRI-based comparison revealed a thyroid volume of $13.1[10.9 ; 20.5] \mathrm{cm}^{3}$, which then decreased to $10.8[10.8 ; 17] \mathrm{cm}^{3}$ during follow-up. The CT-based comparison revealed an initial thyroid volume of 15.5 [12; $22.7] \mathrm{cm}^{3}$. The CT-based thyroid volume during follow-up was $12.5[12.5 ; 16.2] \mathrm{cm}^{3}$. In the entire cohort, a relevant volume loss occurred during follow-up $(p=0.004)$ without differences between the study arms $(p=0.62)$.

Table 1 summarizes the main dosimetric parameters and Fig. 3 shows the comparison of thyroid DVH for the entire patient cohort.

\section{Uni- and multivariable analysis: normal tissue complication probability (NTCP) model}

Before starting the univariable regression analysis, previously published models were tested on our dataset. Firstly, we tested the model by Rønjom et al. [28], receiving an AUC of 0.77 (95\% CI: $0.62-0.88)$ with a sensitivity 
Table 1 Pretreatment baseline patient characteristics

\begin{tabular}{|c|c|c|c|c|c|}
\hline & \multicolumn{2}{|c|}{$\begin{array}{l}\text { Arm A } \\
\text { Intervention group }\end{array}$} & \multicolumn{2}{|c|}{$\begin{array}{l}\text { Arm B } \\
\text { Control group } \\
\end{array}$} & \multirow{3}{*}{$\begin{array}{l}p \text {-value } \\
0.88\end{array}$} \\
\hline & Number & $\%$ & Number & $\%$ & \\
\hline & $n=22$ & 47.8 & $n=24$ & 52.2 & \\
\hline Age & & & & & 0.96 \\
\hline$\leq 60$ years & 9 & 40.9 & 10 & 41.7 & \\
\hline$>60$ years & 13 & 59.1 & 14 & 58.3 & \\
\hline Gender: Male & 16 & 72.7 & 16 & 66.7 & 0.75 \\
\hline Karnofsky performance status & & & & & 0.35 \\
\hline$<80 \%$ & 1 & 4.5 & 4 & 16.7 & \\
\hline$\geq 80 \%$ & 21 & 95.5 & 20 & 83.3 & \\
\hline Diabetes mellitus & 0 & 0 & 3 & 12.5 & 0.24 \\
\hline Primary site & & & & & 0.07 \\
\hline a) Oropharynx & 16 & 72.7 & 12 & 50 & \\
\hline b) Oral cavity & 1 & 4.5 & 7 & 29.2 & \\
\hline c) Hypopharynx & 0 & 0 & 3 & 12.5 & \\
\hline d) Larynx & 3 & 13.6 & 2 & 8.3 & \\
\hline e) Other & 2 & 9 & 0 & 0 & \\
\hline UICC classification & & & & & 0.96 \\
\hline I & 8 & 36.4 & 8 & 33.3 & \\
\hline II & 4 & 18.2 & 6 & 25 & \\
\hline III & 3 & 13.6 & 3 & 12.5 & \\
\hline IV & 7 & 31.8 & 7 & 29.2 & \\
\hline T-classification & & & & & 0.15 \\
\hline $\mathrm{T} 1$ & 2 & 9.1 & 6 & 25 & \\
\hline $\mathrm{T} 2$ & 12 & 54.5 & 9 & 37.5 & \\
\hline $\mathrm{T} 3$ & 2 & 9.1 & 6 & 25 & \\
\hline $\mathrm{T} 4$ & 6 & 27.3 & 3 & 12.5 & \\
\hline$N$-classification & & & & & 0.3 \\
\hline No & 3 & 13.6 & 5 & 20.8 & \\
\hline N1 & 9 & 40.9 & 11 & 45.8 & \\
\hline $\mathrm{N} 2$ & 7 & 31.8 & 8 & 33.3 & \\
\hline N3 & 3 & 13.6 & 0 & 0 & \\
\hline \multicolumn{6}{|l|}{ (Chemo)radiotherapy } \\
\hline Treatment mode & & & & & 0.56 \\
\hline \multicolumn{6}{|l|}{ a) Primary } \\
\hline - Concurrent chemotherapy & 10 & 45.5 & 7 & 29.2 & \\
\hline - RT alone & 2 & 9 & 3 & 12.5 & \\
\hline \multicolumn{6}{|l|}{ b) Adjuvant } \\
\hline - Concurrent chemotherapy & 6 & 27.3 & 5 & 20.8 & \\
\hline - RT alone & 4 & 18.2 & 9 & 37.5 & \\
\hline \multicolumn{5}{|c|}{ Concurrent chemotherapy (as initially prescribed): } & 0.42 \\
\hline Cisplatin $100 \mathrm{mg} / \mathrm{m}^{2} 3$-weekly & 4 & 18.2 & 5 & 20.8 & \\
\hline Cisplatin $40 \mathrm{mg} / \mathrm{m}^{2}$ weekly & 9 & 40.9 & 7 & 29.2 & \\
\hline 5-FU/mitomycin C & 2 & 9.1 & 0 & 0 & \\
\hline Cetuximab & 1 & 4.5 & 0 & 0 & \\
\hline Cisplatin dose & & & & & 0.67 \\
\hline$<200 \mathrm{mg} / \mathrm{m}^{2}$ & 3 & 13.6 & 4 & 16.8 & \\
\hline$\geq 200 \mathrm{mg} / \mathrm{m}^{2}$ & 10 & 76.9 & 8 & 33.3 & \\
\hline
\end{tabular}


Table 1 (Continued)

\begin{tabular}{|c|c|c|c|c|c|}
\hline & \multicolumn{2}{|l|}{$\begin{array}{l}\text { Arm A } \\
\text { Intervention group }\end{array}$} & \multicolumn{2}{|l|}{$\begin{array}{l}\text { Arm B } \\
\text { Control group } \\
\end{array}$} & \multirow{3}{*}{$\begin{array}{l}p \text {-value } \\
0.88\end{array}$} \\
\hline & Number & $\%$ & Number & $\%$ & \\
\hline & $n=22$ & 47.8 & $n=24$ & 52.2 & \\
\hline$R T$ to the neck & & & & & 0.42 \\
\hline Unilateral & 2 & 9 & 5 & 20.8 & \\
\hline Bilateral & 20 & 90.9 & 18 & 75 & \\
\hline None & 0 & 0 & 1 & 4.2 & \\
\hline$R T$ to neck level IV or VI & 20 & 90.9 & 22 & 91.7 & 1 \\
\hline \multicolumn{6}{|l|}{ Nutritional factors } \\
\hline$\Delta$ calorie deficit $(\mathrm{kcal})$ & $117.8[-661.5-737.1]$ & - & $119.5[-383.8 ; 660.1]$ & - & 0.88 \\
\hline$B M I\left(k g / m^{2}\right)$ & $24.1 \pm 5.4$ & - & $24.6 \pm 4$ & - & 0.52 \\
\hline$F F M I\left(k g / m^{2}\right)$ & $18.2[15.9 ; 19.3]$ & - & $17.5[16.2 ; 20.7]$ & - & 0.75 \\
\hline Phase angle $\left({ }^{\circ}\right)$ & $5.1 \pm 1.2$ & - & $5 \pm 0.9$ & - & 0.5 \\
\hline Iodine intake $(\mu g)$ & 175.5 [79.5; 204.5] & - & $126[94 ; 205.3]$ & - & 0.9 \\
\hline Protein intake $(g)$ & $82.2[60.8 ; 109.9]$ & - & $84[64.5 ; 106.2]$ & - & 0.63 \\
\hline Iron intake (mg) & $11[8.9 ; 17.6]$ & - & $12.8[11.7 ; 17.4]$ & - & 0.08 \\
\hline Selenium intake $(\mu \mathrm{g})$ & $12.6[0 ; 57.3]$ & - & $0[0 ; 0]$ & - & $0.023^{a}$ \\
\hline \multicolumn{6}{|l|}{ Laboratory analyses } \\
\hline TSH (reference: $0.55-4.78 \mathrm{mU} / \mathrm{L})$ & $1.49[0.9-2.1]$ & - & $1.21[1 ; 1.80]$ & - & 0.66 \\
\hline Ferritin (reference: $10-291 \mu \mathrm{g} / \mathrm{L}$ ) & $130.4[51.8 ; 418.3]$ & - & $126.5[66.8 ; 263.3]$ & - & 0.8 \\
\hline Hemoglobin (reference: $12.3-15.3 \mathrm{~g} / \mathrm{dL}$ ) & $13.1[12.4 ; 13.7]$ & - & $12.7[11.3 ; 14.2]$ & - & 0.5 \\
\hline Total protein (reference: $57-82 \mathrm{~g} / \mathrm{L}$ ) & $71.8[68.3 ; 77.2]$ & - & $73.6[69.2 ; 97.7]$ & - & 0.37 \\
\hline \multicolumn{6}{|l|}{ Volumetric and dosimetric features } \\
\hline $\begin{array}{l}\text { Volume of thyroid gland }\left(\mathrm{cm}^{3}\right) \text { in planning } \\
C T\end{array}$ & $15.6[10.6 ; 21.9]$ & - & $14[9.2 ; 20.5]$ & - & 0.64 \\
\hline Prescribed PTV high dose & & & & & 0.96 \\
\hline $60 \mathrm{~Gy}$ & 5 & 22.7 & 6 & 25 & \\
\hline $66 \mathrm{~Gy}$ & 6 & 27.3 & 7 & 29.2 & \\
\hline$\geq 70$ Gy & 11 & 50 & 11 & 45.8 & \\
\hline$D_{\text {mean }}$ of thyroid gland $(G y)$ & $50 \pm 12.2$ & - & $46.8 \pm 13.9$ & - & 0.52 \\
\hline$D_{\min }$ of thyroid gland $(G y)$ & $40.8[22.1 ; 46.2]$ & - & $37.3[9.2 ; 48.3]$ & - & 0.74 \\
\hline$D_{\max }$ of thyroid gland (Gy) & $62.5[56.2 ; 68]$ & - & $62.7[57.1 ; 66.4]$ & - & 0.81 \\
\hline
\end{tabular}

$R T$ radiotherapy, UICC Union Internationale Contre le Cancer, 5-FU 5-fluorouracil, $\Delta$ calorie deficit difference between the patient's actual calorie intake and the calculated calories required to maintain body weight (kcal), BMI body mass index, FFMI fat-free mass index, TSH thyroidstimulating hormone, $P T V$ planning target volume, $D_{\text {mean }}(G y)$ mean dose, $D_{\min }(G y)$ minimum dose, $D_{\max }$ maximum dose

${ }^{a}$ Regarding selenium intake at the end of therapy, no differences were present any more between the two groups $(p=0.92)$. TNM staging was performed according to UICC 8 . Values in the square brackets correspond to the first and third quartiles of the interquartile range (IQR).

Fig. 2 Kaplan-Meier curves on the cumulative incidence of hypothyroidism (a) and overall survival (b) for all patients. Cumulative 1- and 2-year incidence for hypothyroidism was $21.3 \%$ and $85.9 \%$, respectively. For overall survival, cumulative percentage of alive patients was $88.9 \%$ after 7 months a Incidence of hypothyroidism

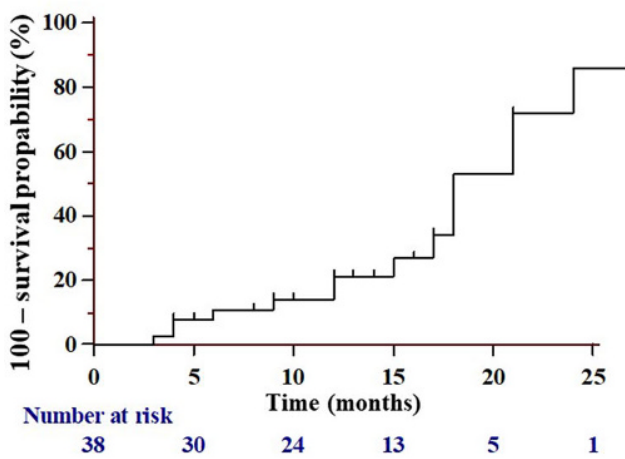

b

\section{Overall survival}

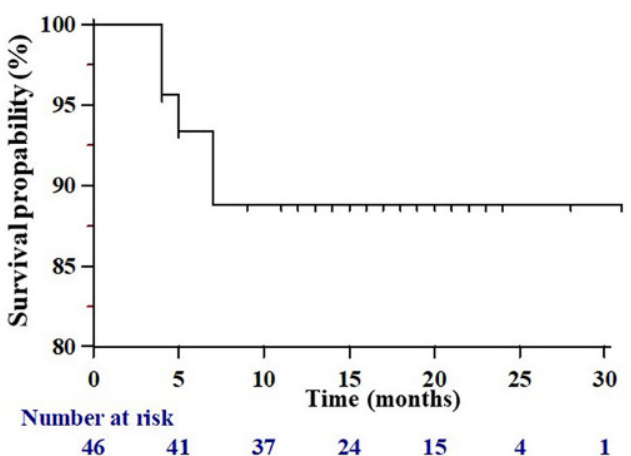


Fig. 3 Dose-volume histograms for the thyroid gland in unilaterally (a, blue) and bilaterally (b, red) irradiated patients. IQR Interquartile range
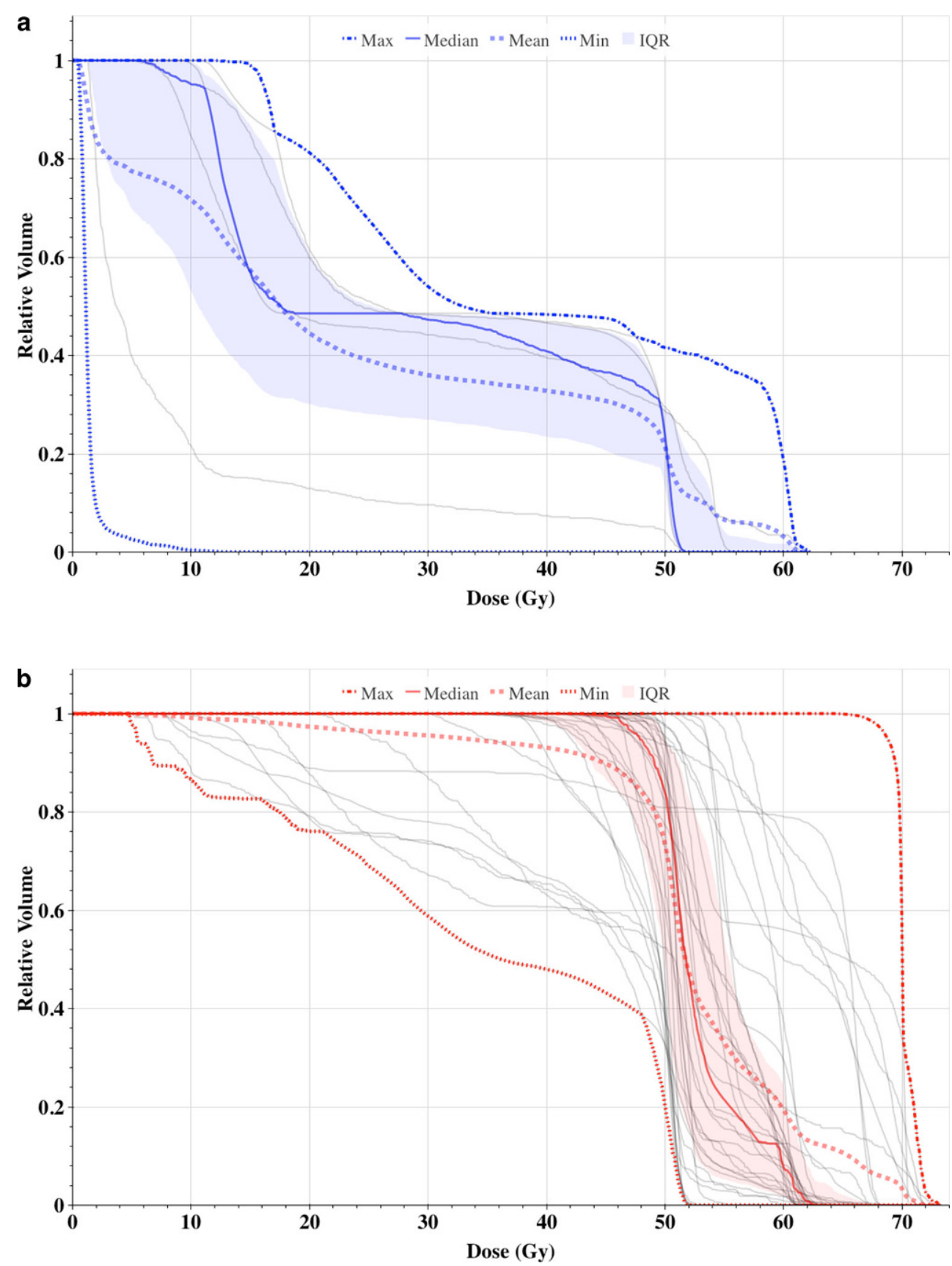

of $85.7 \%$ and specificity of $62.5 \%$ (Youden index: 0.48 ; $p=0.001$ for area $=0.5$ ). Secondly, we applied the proposed NTCP model by Cella et al., who had published two different models. Our chosen model contained gender and V30 Gy $\left(\mathrm{cm}^{3}\right)$ as candidate variables. We received an AUC of 0.76 (95\% CI: $0.61-0.87$ ), and a sensitivity of $78.6 \%$ and specificity of $71.9 \%$ (Youden index: $0.5 ; p=0.001$ for area $=0.5$ ). Thirdly, the NTCP model by Boomsma et al. was tested on our dataset to give an AUC of 0.78 (95\% CI: $0.63-0.89$ ) and, taking a Youden index of 0.5 , a sensitivity of $78.6 \%$ and specificity of $71.9 \%$ resulted $(p<0.001$ for area $=0.5$ ).

Results from the univariable regression analyses with all variables are shown in Table 2 . We did not identify any dosimetric factors associated with the development of hypothyroidism. The following variables showed $p$-values $<0.05$ : baseline iodine intake, $\Delta$ iodine intake, baseline TSH and baseline ferritin level, as well as TSH and ferritin levels at the end of therapy. These parameters were entered into four consecutive multivariable regression models. 
Table 2 Results from the univariable and multivariable logistic regression analysis
Univariable logistic regression analysis

Regression coef- Odds ratio

ficient

CI of the

$p$-value odds ratio

General characteristics

Treatment arm

0.15

Intervention group

$-0.97$

N/A

0.38

$0.1-1.4$

Control group

0.38

0.61

Male

$-0.35$

0.7

N/A

Female

N/A

1.42

$0.19-1.68$

Age

$\leq 60$ years

0.51

N/A

0.17

1.77

0.6

1.0

N/A

Karnofsky performance status (continuous)

T-classification

T1-2

$-3.6$

T3-4

N/A

0.7

1.43

$N$-classification

N0

N/A

0.72

1.39

N1-3

0.33

Definitive

$-0.71$

0.49

2.04

Concurrent systemic treatment

Radiotherapy only

N/A

1.25

0.8

$0.47-5.93$

N/A

$0.96-1.1$

0.19-2.53

N/A

N/A

0.24-7.89

0.13-1.79

N/A

N/A

$-0.22$

N/A

$0.22-2.87$

Cumulative cisplatin dose

$<200 \mathrm{mg} / \mathrm{m}^{2}$

$\geq 200 \mathrm{mg} / \mathrm{m}^{2}$

N/A

$-0.04$

1.04

0.96

N/A

Diabetes mellitus ${ }^{\mathrm{a}}$

Yes

$-20.48^{\mathrm{a}}$

N/A

$-^{\mathrm{a}}$

0.99

No

RT to neck level IV or VI

Yes

N/A

$-0.3$

1.35

0.74

0.14-6.67

$0-0.07^{\mathrm{a}}$

N/A

N/A

$0.07-7.84$

$R T$ to the neck ${ }^{\mathrm{a}}$

Unilateral

$-20.7^{\mathrm{a}}$

N/A

$-^{\mathrm{a}}$

1

Bilateral

Nutritional factors

$\Delta$ calorie deficit (kcal) at two different time points (continuous variable)

Baseline 0

End of therapy

0

1

$1-1.001$

0.25

Iodine intake $(\mu \mathrm{g})$ at two different timepoints (continuous variable)

Baseline

0.01

End of therapy

$-0.003$

$\Delta$ iodine intake

0.005

Protein intake ( $g$ ) at two different timepoints (continuous variable)

\begin{tabular}{lllll} 
Baseline & 0.01 & 1.01 & $0.99-1.02$ & 0.35 \\
End of therapy & -0.01 & 0.99 & $0.98-1.01$ & 0.51 \\
\hline
\end{tabular}


Table 2 (Continued)

\begin{tabular}{|c|c|c|c|c|}
\hline & \multicolumn{4}{|c|}{ Univariable logistic regression analysis } \\
\hline & $\begin{array}{l}\text { Regression coef- } \\
\text { ficient }\end{array}$ & Odds ratio & $\begin{array}{l}95 \% \mathrm{CI} \text { of the } \\
\text { odds ratio }\end{array}$ & $p$-value \\
\hline \multicolumn{5}{|c|}{$\begin{array}{l}\text { Iron intake ( } \mathrm{mg} \text { ) at two different timepoints } \\
\text { (continuous variable) }\end{array}$} \\
\hline Baseline & 0.05 & 1.05 & $0.92-1.19$ & 0.49 \\
\hline End of therapy & -0.06 & 0.23 & $0.86-1.04$ & 0.23 \\
\hline \multicolumn{5}{|c|}{$\begin{array}{l}\text { Selenium intake }(\mu g) \text { at two different timepoints } \\
\text { (continuous variable) }\end{array}$} \\
\hline Baseline & 0.01 & 1.01 & $0.98-1.03$ & 0.68 \\
\hline End of therapy & 0 & 1 & $0.98-1.02$ & 0.96 \\
\hline \multicolumn{5}{|c|}{$\begin{array}{l}\text { BMI }\left(\mathrm{kg} / \mathrm{m}^{2}\right) \text { at four different timepoints } \\
\text { (continuous variable) }\end{array}$} \\
\hline Baseline & 0.07 & 1.07 & $0.94-1.22$ & 0.31 \\
\hline End of therapy & 0.07 & 1.08 & $0.92-1.26$ & 0.36 \\
\hline $\begin{array}{l}\text { First follow-up ( } 6-8 \text { weeks } \\
\text { after therapy) }\end{array}$ & -0.21 & 0.81 & $0.6-1.09$ & 0.17 \\
\hline $\begin{array}{l}\text { Second follow-up ( } 8 \text { months } \\
\text { after therapy) }\end{array}$ & 0.002 & 1 & $0.74-1.35$ & 0.99 \\
\hline \multicolumn{5}{|c|}{$\begin{array}{l}\text { FFMI }\left(\mathrm{kg} / \mathrm{m}^{2}\right) \text { at four different timepoints } \\
\text { (continuous variable) }\end{array}$} \\
\hline Baseline & -0.01 & 0.99 & $0.78-1.25$ & 0.92 \\
\hline End of therapy & -0.04 & 0.96 & $0.71-1.29$ & 0.79 \\
\hline $\begin{array}{l}\text { First follow-up ( } 6-8 \text { weeks } \\
\text { after therapy) }\end{array}$ & -0.21 & 0.81 & $0.6-1.09$ & 0.17 \\
\hline $\begin{array}{l}\text { Second follow-up ( } 8 \text { months } \\
\text { after therapy) }\end{array}$ & -0.24 & 0.79 & $0.53-1.19$ & 0.26 \\
\hline \multicolumn{5}{|c|}{$\begin{array}{l}\text { Phase angle }\left({ }^{\circ} \text { ) at four different timepoints }\right. \\
\text { (continuous variable) }\end{array}$} \\
\hline Baseline & -0.11 & 0.9 & $0.48-1.69$ & 0.73 \\
\hline End of therapy & -0.17 & 0.85 & $0.46-1.55$ & 0.59 \\
\hline $\begin{array}{l}\text { First follow-up ( } 6-8 \text { weeks } \\
\text { after therapy) }\end{array}$ & -0.81 & 0.44 & $0.19-1.06$ & 0.07 \\
\hline $\begin{array}{l}\text { Second follow-up ( } 8 \text { months } \\
\text { after therapy) }\end{array}$ & -0.71 & 0.49 & $0.17-1.39$ & 0.18 \\
\hline \multicolumn{5}{|l|}{ Laboratory analyses } \\
\hline \multicolumn{5}{|l|}{ TSH (mU/L) } \\
\hline - Baseline & 1.34 & 3.82 & $1.32-11.02$ & 0.013 \\
\hline - End of therapy & 0.74 & 2.09 & 1.1-3.98 & 0.024 \\
\hline$-\Delta \mathrm{TSH}$ & -0.47 & 0.46 & $0.34-1.15$ & 0.13 \\
\hline \multicolumn{5}{|l|}{ Ferritin level $(\mu \mathrm{g} / \mathrm{L})$} \\
\hline - Baseline & 0.004 & 1.004 & 1-1.008 & 0.048 \\
\hline - End of therapy & 0.003 & 1.003 & 1-1.006 & 0.042 \\
\hline$-\Delta$ ferritin & 0.002 & 1 & $1-1.01$ & 0.39 \\
\hline \multicolumn{5}{|l|}{ Total protein $(g / L)$} \\
\hline Baseline & 0.07 & 1.07 & $0.97-1.19$ & 0.19 \\
\hline End of therapy & 0.06 & 1.06 & $0.96-1.17$ & 0.26 \\
\hline \multicolumn{5}{|l|}{ Hemoglobin $(\mathrm{g} / \mathrm{dL})$} \\
\hline Baseline & -0.34 & 0.72 & $0.46-1.11$ & 0.14 \\
\hline End of therapy & -0.22 & 0.8 & $0.59-1.11$ & 0.18 \\
\hline \multicolumn{5}{|c|}{ Volumetric and dosimetric indicators of the thyroid gland (at baseline) } \\
\hline $\begin{array}{l}\text { Volume }\left(\mathrm{cm}^{3}\right) \text { in planning } \mathrm{CT} \\
\text { (continuous) }\end{array}$ & -0.1 & 0.9 & $0.81-1.01$ & 0.07 \\
\hline
\end{tabular}


Table 2 (Continued)

\begin{tabular}{|c|c|c|c|c|}
\hline & \multicolumn{4}{|c|}{ Univariable logistic regression analysis } \\
\hline & $\begin{array}{l}\text { Regression coef- } \\
\text { ficient }\end{array}$ & Odds ratio & $\begin{array}{l}95 \% \text { CI of the } \\
\text { odds ratio }\end{array}$ & $p$-value \\
\hline \multicolumn{5}{|c|}{ Dosimetric indicators (Gy; continuous) } \\
\hline Prescribed PTV high dose & -0.08 & 0.93 & $0.79-1.09$ & 0.35 \\
\hline $\mathrm{D}_{\text {mean }}$ & 0.04 & 1.04 & $0.98-1.11$ & 0.2 \\
\hline $\mathrm{D}_{\min }$ & 0.04 & 1.04 & $1-1.09$ & 0.051 \\
\hline $\mathrm{D}_{\max }$ & 0.01 & 1.01 & $0.94-1.09$ & 0.73 \\
\hline D99\% & 0.04 & 1.04 & $1-1.08$ & 0.08 \\
\hline D98\% & 0.04 & 1.04 & $1-1.08$ & 0.09 \\
\hline D50\% & 0.04 & 1.04 & $0.98-1.1$ & 0.21 \\
\hline D95\% & 0.02 & 1.02 & $0.93-1.12$ & 0.64 \\
\hline D1\% & 0.02 & 1.02 & $0.95-1.1$ & 0.61 \\
\hline $\mathrm{D} 2 \%$ & 0.02 & 1.02 & $0.95-1.1$ & 0.63 \\
\hline \multicolumn{5}{|l|}{ VxGy $\left(\mathrm{cm}^{3} ;\right.$ continuous $)$} \\
\hline V10Gy & -0.06 & 0.94 & $0.86-1.03$ & 0.16 \\
\hline V20Gy & -0.05 & 0.95 & $0.88-1.03$ & 0.25 \\
\hline V30Gy & -0.04 & 0.96 & $0.89-1.04$ & 0.29 \\
\hline V40Gy & -0.04 & 0.96 & $0.89-1.04$ & 0.33 \\
\hline V45Gy & -0.03 & 0.97 & $0.9-1.05$ & 0.4 \\
\hline V50Gy & -0.02 & 0.98 & $0.9-1.07$ & 0.67 \\
\hline V60Gy & -0.05 & 0.95 & $0.8-1.13$ & 0.56 \\
\hline V70Gy & 0.003 & 1 & $0.53-1.9$ & 0.99 \\
\hline \multicolumn{5}{|l|}{ CVxGy ( $\mathrm{cm}^{3}$; continuous $)$} \\
\hline CV10Gy & -0.62 & 0.54 & $1.3-2.27$ & 0.4 \\
\hline CV20Gy & -0.33 & 0.72 & $0.44-1.19$ & 0.19 \\
\hline CV30Gy & -0.25 & 0.78 & $0.55-1.1$ & 0.16 \\
\hline \multirow[t]{3}{*}{ CV40Gy } & -0.22 & 0.8 & $0.59-1.08$ & 0.14 \\
\hline & \multicolumn{4}{|c|}{ Multivariable regression analysis } \\
\hline & $\begin{array}{l}\text { Regression coef- } \\
\text { ficient }\end{array}$ & Odds ratio & $\begin{array}{l}95 \% \text { CI of the } \\
\text { odds ratio }\end{array}$ & $p$-value \\
\hline \multicolumn{5}{|l|}{ Model 1} \\
\hline Baseline ferritin $(\mu \mathrm{g} / \mathrm{L})$ & 0.004 & 1.004 & $1-1.01$ & 0.04 \\
\hline Constant & -1.62 & N/A & N/A & N/A \\
\hline \multicolumn{5}{|l|}{ Model 2} \\
\hline Baseline ferritin $(\mu \mathrm{g} / \mathrm{L})$ & 0.004 & 1.004 & $1-1.01$ & 0.04 \\
\hline \multicolumn{5}{|l|}{ Model 3} \\
\hline Baseline ferritin $(\mu \mathrm{g} / \mathrm{L})$ & 0.005 & 1.005 & $1-1.01$ & 0.05 \\
\hline Baseline TSH (mU/L) & 1.26 & 3.5284 & $1.2-10.41$ & 0.02 \\
\hline Constant & -3.76 & N/A & N/A & N/A \\
\hline \multicolumn{5}{|l|}{ Model 4} \\
\hline Baseline TSH (mU/L) & 1.26 & 3.53 & $1.2-10.41$ & 0.02 \\
\hline Baseline ferritin $(\mu \mathrm{g} / \mathrm{L})$ & 0.01 & 1.01 & $1-1-01$ & 0.05 \\
\hline Constant & -3.76 & N/A & N/A & N/A \\
\hline
\end{tabular}

Results from the univariable and multivariable logistic regression analysis for hypothyroidism. Parameters with $p<0.05$ are written in bold

N/A not applicable, $R T$ radiotherapy, $T S H$ thyroid-stimulating hormone, 95\% CI 95\% confidence interval, $B M I$ body mass index, FFMI fat-free mass index, $V x G y$ thyroid volume $\left(\mathrm{cm}^{3}\right)$ receiving x $G y, C V x G y$ $\left(\mathrm{cm}^{3}\right)$ thyroid volume receiving $\leq \mathrm{x}$ Gy

${ }^{a}$ None of the diabetic and none of the unilaterally irradiated patients presented with the endpoint hypothyroidism. Therefore, the 95\% CI was calculated applying the "rule of three" [35] 


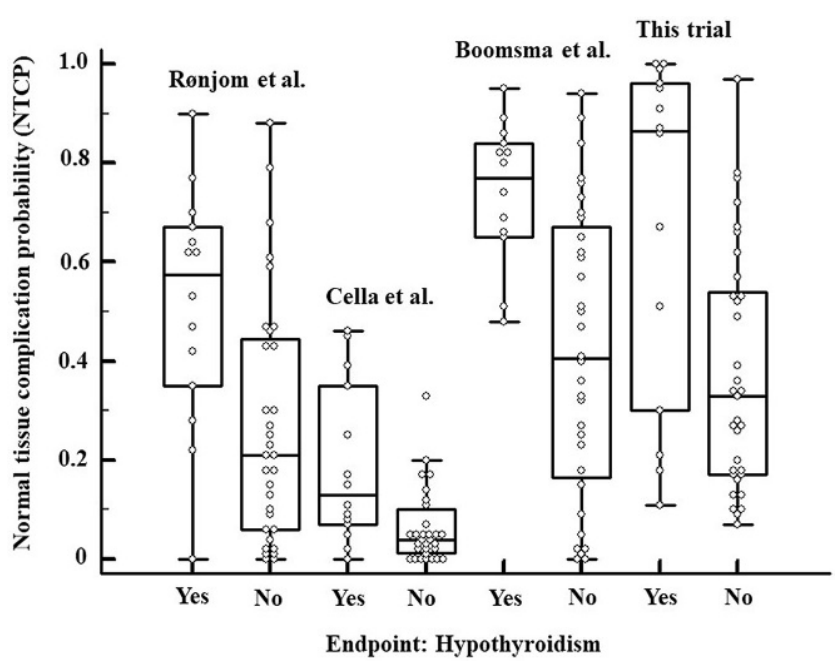

Fig. 4 Boxplot diagrams on the prediction of hypothyroidism applying different NTCP models from Rønjom [28], Cella [29] (only one of the two published models was tested), and Boomsma et al. [7]. Every dot marks one case

Model 1 tested all variables from our univariable regression analysis with $p<0.05$, together with $\mathrm{D}_{\text {mean }}$, thyroid volume V45Gy, V30 Gy, and the study arm, showing an AUC of 0.68 (0.52-0.82). Model 2 consisted of all univariable parameters with $p<0.05, \mathrm{D}_{\text {mean }}$, thyroid volume, V30Gy, and V45Gy. This model revealed an AUC of 0.68 (95\% CI: 0.52-0.82). Model 3 included our univariable parameters (with $p<0.05$ ), $\mathrm{D}_{\text {mean }}$, and thyroid volume. This model showed an AUC of 0.78 (95\% CI: 0.63-0.89). Model 4 consisted of all univariable parameters with $p<0.05$. Here, ROC analysis revealed an AUC of 0.78 (95\% CI: 0.63-0.89). Results from the univariable and multivariable regression analyses are summarized in Table 2.

Our final NTCP model is built on two parameters, namely baseline TSH and ferritin level, as they showed the best predictive potential. Prior to running our multivariable analyses, correlation between these parameters was excluded (correlation coefficient $\mathrm{r}=0.07 ; p=0.64$ ). We derived the following NTCP model:

$$
\begin{aligned}
& \text { NTCP }=\left(1+e^{-S}\right)^{-1}, \text { in which } \\
& S=-3.76+(1.26 \cdot \text { baseline } T S H) \\
& +(0.01 \cdot \text { baseline ferritin level })
\end{aligned}
$$

Application of this NTCP model to our patient population showed an AUC of 0.76 (95\% CI: 0.61-0.87), with a sensitivity of $57.1 \%$ and specificity of $96.9 \%$ calculated for a Youden index of $0.73(p=0.004$; area $=0.5)$. The performance of the present NTCP model compared to other previously published NTCP models can be seen in Fig. 4.

\section{Discussion}

This is the first prospective study including nutritional parameters to develop a new multivariable NTCP model for radiation-induced hypothyroidism. In all previous publications, dosimetric factors always played a decisive role. According to Boomsma and Rønjom et al., $\mathrm{D}_{\text {mean }}$ and the initial thyroid volume were predictors for hypothyroidism [7, 28]. In accordance, Emami et al. assumed the onset of hypothyroidism when $2 / 3$ of the thyroid gland was damaged [4]. Although we noticed a reduction in thyroid volume during follow-up, we could not prove thyroid volume to be an independent predictor of hypothyroidism. Still, both models showed good performance in our dataset (Boomsma: $\mathrm{AUC}=0.78$, Rønjom: $\mathrm{AUC}=0.77$ ).

To allow a dosimetric approach, we included dosimetric and volumetric parameters in models $1-3$, analogous to previously published data $\left(\mathrm{D}_{\text {mean }}\right.$, thyroid volume, V30 Gy, and V45 Gy) [2, 5-8, 28, 29]. These parameters were eliminated from all three models and only baseline TSH and ferritin level prevailed (see Table 2). Although TSH was the leading factor in our NTCP model (multiplication factor for TSH was 1.26 vs. 0.01 for ferritin), both increased TSH and ferritin levels were associated with an increasing risk of hypothyroidism. Although Rønjom et al. also tested the influence of baseline TSH, it was a nonpredictor for hypothyroidism [28]. Overall, many of our investigated parameters have simply not been tested before [7, 28, 29], and the influence of these parameters remains unclear, suggesting an underrepresentation in previous NTCP models.

The undersupply of certain macro- and micronutrients appears to be a crucial risk factor for thyroid dysfunction $[10-13,15,32]$. Iron deficiency is one of the most common deficiency symptoms worldwide, which may manifest not only as iron deficiency anemia, but also in the form of low ferritin levels, thus negatively affecting thyroid metabolism $[12,13,32]$. This mainly happens through reduced thyroid hormone synthesis by the heme-dependent enzyme thyroid peroxidase (TPO) $[11,12,32]$. Conversely, in our patients, higher baseline ferritin positively correlated with hypothyroidism. Ferritin is also known as acute-phase protein. It isolates iron, protecting it from bacterial abduction to stop further bacterial growth. During inflammatory or malignant processes, ferritin is upregulated to hide free iron from cancer cells or bacteria [33]. Since all our patients suffered from an underlying malignant disease, higher ferritin levels were common. If we now relate the iron and ferritin balance, we suppose that higher ferritin levels lead to lower iron levels in the long term, and thus interfere with thyroid hormone synthesis by influencing heme-dependent TPO. Iodine intake is considered another crucial factor for thyroid metabolism because it constitutes $59 \%$ and $65 \%$ of fT3 and fT4, respectively [11]. Although we expected a certain 
influence of iodine intake on the development of hypothyroidism, we could not prove this in our multivariable analysis.

As the risk for radiation-induced hypothyroidism increases with time, Boomsma et al. reported on a cumulative 2-year incidence of $36 \%$. In comparison, we observed a cumulative 1- and 2-year incidence of $21.3 \%$ and $85.9 \%$, respectively. We are aware that especially our 2-year incidence is noticeably higher than that of Boomsma et al. We believe that this is partly biased by our shorter TSH-specific follow-up time of 13.5 [8.8; 17] months (Boomsma et al.: 2.49 years, range: $0.33-3.30$ [7]) and by the underdiagnosis of hypothyroidism during the corona pandemic. Due to the corona pandemic and during the general lockdown in XXX, blood sampling for TSH follow-up took place later. Therefore, we suspect that this resulted in a steep increase in incidence after approximately 15 months. Our assumption is that hypothyroidism had been diagnosed earlier under normal conditions. Cella et al. retrospectively investigated the outcome of 53 patients with Hodgkin's lymphoma. These authors reported on $41.5 \%$ of patients presenting with hypothyroidism after a median follow-up time of 32 months (range 6-99) after completion of radiotherapy [29]. For patients with nasopharyngeal cancer, Luo et al. reported on $22.4 \%$ of patients suffering from hypothyroidism after a median follow-up of 24 (range 3 to 66) months [34].

Overall, we proved a worsening of nutritional status in the pre- vs. posttherapeutic comparison. Macro- and micronutrient intake did not change during ongoing therapy, except for selenium and protein. As expected, protein intake decreased at the end of therapy $(p=0.028)$, while selenium intake increased $(p=0.002)$. The increased selenium intake might be related to the higher proportion of nutritional supplementation at the end of therapy, e.g., by sip feeds, as they are usually enriched with selenium.

The major limitation of the present study is its small patient number. Usually one would assume a dose-response relationship within the framework of the biological model. We expected a dose dependence in the occurrence of hypothyroidism after irradiation. The observation that none of the 7 patients with unilateral irradiation (implicitly lower dose) developed hypothyroidism suggests a dose effect. Since the group is small, with 7 patients, masking of the dose is conceivable. Nevertheless, no statistic differences were obtained in the comparison to bilaterally irradiated patients. Of course, it is important to critically question whether a dose dependence would be statistically present in a bigger patient cohort. To achieve a homogeneous patient population, we subjected our patients to a very strict selection process (see CONSORT diagram) and excluded all patients with possible pre-existing diseases of the thyroid gland from the analysis. In the statistical evaluation and calculation of a multivariable logistic regression model, all variables introduced into the model are crucial. Since there are various possible metabolic and nutritional factors influencing thyroid gland metabolism, we included them in our analysis. Some of these metabolic parameters were entered into a NTCP model for the first time. This could have led to an overestimation of the dose effect in contrast to previously undetected metabolic phenomena in earlier published data.

We conclude that laboratory chemical parameters, namely baseline TSH and ferritin, act as independent predictors for the occurrence of radiotherapy-associated hypothyroidism. The addition of laboratory chemical analyses to dosimetric and clinical parameters could improve the accuracy and validity of future NTCP models.

Funding Open Access funding enabled and organized by Projekt DEAL.

\section{Declarations}

Conflict of interest A. Löser, K. Ramke, M. Grohmann, L. Krause, P. Roser, F. Greinert, A. Finger, M. Sommer, E. Culmann, T. Lorenz, S. Becker, M. Henze, D. Schodrok, J. von Grundherr, S. Tribius, A. Krüll, and C. Petersen declare that they have no competing interests.

Ethical standards The approval of the local ethics committee was obtained (PV5818) before the beginning of the study on 10/30/2018. Consent to participate: All included patients signed written informed consent. Consent for publication: Consent for publication was obtained from all authors.

Open Access This article is licensed under a Creative Commons Attribution 4.0 International License, which permits use, sharing, adaptation, distribution and reproduction in any medium or format, as long as you give appropriate credit to the original author(s) and the source, provide a link to the Creative Commons licence, and indicate if changes were made. The images or other third party material in this article are included in the article's Creative Commons licence, unless indicated otherwise in a credit line to the material. If material is not included in the article's Creative Commons licence and your intended use is not permitted by statutory regulation or exceeds the permitted use, you will need to obtain permission directly from the copyright holder. To view a copy of this licence, visit http://creativecommons.org/licenses/by/4. $0 /$.

\section{References}

1. Jereczek-Fossa BA, Alterio D, Jassem J et al (2004) Radiotherapyinduced thyroid disorders. Cancer Treat Rev 30:369-384

2. Zhou L, Chen J, Tao C-J et al (2021) Research progress of radiation-induced hypothyroidism in head and neck cancer. J Cancer 12:451-459

3. Hancock SL, McDougall IR, Constine LS (1995) Thyroid abnormalities after therapeutic external radiation. Int J Radiat Oncol Biol Phys 31:1165-1170

4. Emami B, Lyman J, Brown A, Coia L, Goitein M, Munzenrider JE et al (1991) Tolerance of normal tissue to therapeutic irradiation. Int J Radiat Oncol Biol Phys 21(1):109-122 
5. Fujiwara M, Kamikonya N, Odawara S et al (2015) The threshold of hypothyroidism after radiation therapy for head and neck cancer: a retrospective analysis of 116 cases. J Radiat Res 56:577-582

6. Kim MY, Yu T, Wu H-G (2014) Dose-volumetric parameters for predicting hypothyroidism after radiotherapy for head and neck cancer. Jpn J Clin Oncol 44:331-337

7. Boomsma MJ, Bijl HP, Christianen ME et al (2012) A prospective cohort study on radiation-induced hypothyroidism: development of an NTCP model. Int J Radiat Oncol Biol Phys 84:e351-6

8. Diaz R, Jaboin JJ, Morales-Paliza M et al (2010) Hypothyroidism as a consequence of intensity-modulated radiotherapy with concurrent taxane-based chemotherapy for locally advanced head-andneck cancer. Int J Radiat Oncol Biol Phys 77:468-476

9. Rayman MP (2019) Multiple nutritional factors and thyroid disease, with particular reference to autoimmune thyroid disease. Proc Nutr Soc 78:34-44

10. Hu S, Rayman MP (2017) Multiple nutritional factors and the risk of Hashimoto's thyroiditis. Thyroid 27:597-610

11. Dunn JT, Dunn AD (2001) Update on intrathyroidal iodine metabolism. Thyroid 11:407-414

12. Hess SY, Zimmermann MB, Arnold M et al (2002) Iron deficiency anemia reduces thyroid peroxidase activity in rats. J Nutr 132:1951-1955

13. Luo J, Wang X, Yuan L et al (2021) Iron deficiency, a risk factor of thyroid disorders in reproductive-age and pregnant women: a systematic review and meta-analysis. Front Endocrinol (Lausanne) 12:629831

14. Ventura M, Melo M, Carrilho F (2017) Selenium and thyroid disease: from pathophysiology to treatment. Int $\mathrm{J}$ Endocrinol 2017:1297658

15. Tahara Y, Hirota M, Shima K et al (1988) Primary hypothyroidism in an adult patient with protein-calorie malnutrition: a study of its mechanism and the effect of amino acid deficiency. Metabolism 37:9-14

16. Unsal D, Mentes B, Akmansu M et al (2006) Evaluation of nutritional status in cancer patients receiving radiotherapy: a prospective study. Am J Clin Oncol 29:183-188

17. Langius JAE, Doornaert P, Spreeuwenberg MD et al (2010) Radiotherapy on the neck nodes predicts severe weight loss in patients with early stage laryngeal cancer. Radiat Oncol 97:80-85

18. Gorenc M, Kozjek NR, Strojan P (2015) Malnutrition and cachexia in patients with head and neck cancer treated with (chemo)radiotherapy. Rep Pract Oncol Radiother 20:249-258

19. Kinclová I, Hajtmanová E, Matula P et al (2020) Model-based calculation of thyroid gland normal tissue complication probability in head and neck cancer patients after radiation therapy. Strahlenther Onkol 196:561-568

20. Löser A, Abel J, Kutz LM et al (2021) Head and neck cancer patients under (chemo-)radiotherapy undergoing nutritional intervention: results from the prospective randomized HEADNUT-trial. Radiat Oncol 159:82-90

21. Kohli K, Corns R, Vinnakota K et al (2018) A bioimpedance analysis of head-and-neck cancer patients undergoing radiotherapy. Curr Oncol 25:e193-e199
22. Schutz Y, Kyle UUG, Pichard C (2002) Fat-free mass index and fat mass index percentiles in Caucasians aged 18-98 y. Int J Obes Relat Metab Disord 26:953-960

23. Siddiqui NI, Khan SA, Shoeb M et al (2016) Anthropometric predictors of bio-impedance analysis (BIA) phase angle in healthy adults. J Clin Diagn Res 10:CC1-4

24. Grundmann O, Yoon SL, Williams JJ (2015) The value of bioelectrical impedance analysis and phase angle in the evaluation of malnutrition and quality of life in cancer patients-a comprehensive review. Eur J Clin Nutr 69:1290-1297

25. Mayo CS, Moran JM, Bosch W et al (2018) American association of physicists in medicine task group 263: standardizing nomenclatures in radiation oncology. Int J Radiat Oncol Biol Phys 100:1057-1066

26. Grégoire V, Grau C, Lapeyre M et al (2018) Target volume selection and delineation ( $\mathrm{T}$ and $\mathrm{N}$ ) for primary radiation treatment of oral cavity, oropharyngeal, hypopharyngeal and laryngeal squamous cell carcinoma. Oral Oncol 87:131-137

27. Jensen K, Friborg J, Hansen CR et al (2020) The Danish head and neck cancer group (DAHANCA) 2020 radiotherapy guidelines. Radiat Oncol 151:149-151

28. Rønjom MF, Brink C, Bentzen SM et al (2013) Hypothyroidism after primary radiotherapy for head and neck squamous cell carcinoma: normal tissue complication probability modeling with latent time correction. Radiat Oncol 109:317-322

29. Cella L, Liuzzi R, Conson M et al (2012) Development of multivariate NTCP models for radiation-induced hypothyroidism: a comparative analysis. Radiat Oncol 7:224

30. Steyerberg EW, Vickers AJ, Cook NR et al (2010) Assessing the performance of prediction models: a framework for traditional and novel measures. Epidemiology 21:128-138

31. Cutright D, Gopalakrishnan M, Roy A et al (2018) DVH analytics: a DVH database for clinicians and researchers. J Appl Clin Med Phys 19:413-427

32. Zimmermann MB, Burgi H, Hurrell RF (2007) Iron deficiency predicts poor maternal thyroid status during pregnancy. J Clin Endocrinol Metab 92:3436-3440

33. Gulhar R, Ashraf MA, Jialal I (2020) Physiology, acute phase reactants. https://www.ncbi.nlm.nih.gov/books/NBK519570/. Accessed 24 Apr 2021

34. Luo R, Wu VWC, He B et al (2018) Development of a normal tissue complication probability (NTCP) model for radiation-induced hypothyroidism in nasopharyngeal carcinoma patients. BMC Cancer 18:575

35. Jovanovic BD, Levy PS (1997) A look at the rule of three. Am Stat $51: 137-139$

36. CONsolidated Standards Of Reporting Trials (2020) The CONSORT flow diagram. http://www.consort-statement.org/consort-statement/ flow-diagram. Accessed 4 Dec 2020 